\title{
THE EFFECT OF TRANSFORMATIONAL LEADERSHIP, ORGANIZATIONAL CULTURE AND STRATEGIC ORIENTATION ON ORGANIZATIONAL PERFORMANCE THROUGH THE MEDIATING ROLE OF KNOWLEDGE MANAGEMENT: A STUDY IN REGIONAL WATER SUPPLY COMPANIES OF WEST NUSA TENGGARA, INDONESIA
}

\author{
Hermanto* \\ Doctorate Program of Management, University of Brawijaya, Malang, Indonesia \\ Moeljadi, Troena Eka Afnan, Rofiaty \\ Management Department, Faculty of Economic and Business, University of Brawijaya, \\ Malang, Indonesia \\ *E-mail: hermanto2307@gmail.com
}

\begin{abstract}
This study aims to examine and to explain the direct impact of transformational leadership, organizational culture, and strategic orientation on organizational performance, as well as indirect impact of those variables through the mediating role of knowledge management. A quantitative approach is applied where data are collected based on a survey method; in addition, the analysis technique uses General Structured Component Analysis. All regional water supply companies in West Nusa Tenggara are involved as the unit analysis of this research in which 70 managers at top and middle level are treated as research respondents. The research indicates that there is a positive and significant direct effect of knowledge management on organizational performance; yet there is no direct effect of transformational leadership, organizational culture, and strategic orientation on organizational performance. The result also demonstrates that knowledge management is a full mediation variable of organizational culture and strategic orientation on organizational performance, but not on the relationship between transformational leadership and organizational performance. However, in order to provide more comprehensive results, further research of study needed to involve more regional water companies as unit analysis as well as another knowledge management's drivers in order to broaden the perspective of knowledge management role.
\end{abstract}

\section{KEY WORDS}

Transformational leadership, organizational culture, strategic orientation, knowledge management, organizational performance.

The core concept of transformational leadership is transformation, or change of the organization, so Tichy and Devanna (1986) said that companies were being asked to make fundamental changes. Burns (1978) defined transformational leadership as a process in which leaders and followers raise one another to higher levels of morality and motivation and transformational leadership best reflects this changes. According to Bass (1985-1990), Avolio and Bass (2002), there are four behaviors that form the basis of transformational leadership: idealized influence, inspirational motivation, intellectual stimulation, and individualized consideration. Idealized influence involves setting an example for followers to follow. This style can be regarded in terms of "behavior and attributes". It refers to the charismatic behavior shown by transformational leaders who express confidence in the organizational vision (Antonakis et al., 2003). Under inspirational motivation, leaders try to inspire their followers by motivating them to become committed to the organizational vision. They encourage members to focus on organizational objectives, and have the ability to motivate their followers by providing meaning and challenge to their work (Avolio and Bass, 2002, Sashkin, 2004). Intellectual stimulation is the degree to which leaders encourage their followers to try new approaches, and to re-examine and challenge existing assumptions. They encourage imagination, and develop innovative ways of dealing with organizational 
issues (DuBrin, 2012). When implementing individualized consideration leaders build interactive relationships with followers and pay special attention to their needs (Avolio and Bass, 2002, Saenz, 2011). These four behavioral patterns positively affect followers by elevating them to the best they can be, motivated by the desire for achievement and selfdevelopment.

Organizational culture $(\mathrm{OC})$ is defined as the set of shared, taken-for-granted implicit assumptions that a group holds and that determines how it perceives, thinks about, and reacts to its various environments (Schein, 2004). OC can become a source of sustainable competitive advantage if that culture is valuable, rare, and imperfectly imitable (Barney, 1986). Organizational cultures represent the character of an organization, which directs its employees' day-to-day working relationships and guides them on how to behave and communicate within the organization, as well as guiding how the company hierarchy is built (Ribiere and Sitar, 2003). Denison (1990) developed a model of organizational culture and effectiveness based on four traits: involvement, consistency, adaptability and mission. According to Denison, the effectiveness of a company directly linked to organizational culture (Denison,1990).

Business strategy has been characterized as the manner in which a firm decides to compete (Walker and Ruekert, 1987), which encompasses the pursuit, achievement, and maintenance of competitive advantage in an industry (Varadarajan and Clark, 1994). Normative theory in strategy has tended to adopt process, content, or context perspectives (Ketchen et al., 1996). The literature has considered strategic orientation from three viewpoints: the narrative approach endeavors to describe verbally the holistic nature of strategy which is unique to the event, situation, and organization (Czarniawska, 1998); the classificatory approach attempts to classify firms' strategy according to either ex ante conceptual arguments or ex post empirically derived groupings; and the comparative approach (Morgan, 2003) considered strategy in terms of the relative emphasis made by the firm along each strategic orientation dimension. Venkatraman's conceptual of strategic orientation will be used as the basis for the following conceptualization.

Knowledge management is defined as a proactive, systematic process by which value is generated from intellectual or knowledge-based assets and disseminated to the stakeholders.

Swan, J., Scarborough, H., and Preston, J. (1999) defines KM as, “...any process or practice of creating, acquiring, capturing, sharing and using knowledge, wherever it resides, to enhance learning and performance in organizations. Nonaka \& Takeuchi (1995) identifies four possible modes: socialization, externalization, combination, and internalization. Socialization transforms tacit knowledge into new tacit knowledge through social interactions among organizational members. Externalization converts tacit knowledge into explicit notions. Combination is the organizational knowledge creation process whereby individual explicit knowledge is converted to organizational explicit knowledge. Internalization is the conversion of explicit knowledge into the organizational tacit knowledge. To examine knowledge creation process, this study adopts the SECl (socialization, externalization, combination, and internalization) model by Nonaka (1994) for two reasons. First, the SECI model contains not only knowledge transfer but also knowledge creation. Existing knowledge transfer and new knowledge creation are very significant in knowledge management. Second, the SECI model has been widely used in many research areas such as organizational learning and new product development (Lee and Choi, 2003).

Organizational performance is a complex, multi-dimensional phenomenon that is difficult to understand and measure (Goodman and Pennings, 1977). Different organizations have different performance objectives and performance may vary according to the targets set, the time period observed, the criteria used and on whose perspective is being taken (e.g. the customers', the managers', the employees' or the shareholders'). Performance measurement is a complex issue and several researchers have attempted to develop an understanding of the issues relevant to organizational performance and its measurement, (Kaplan and Norton,1996; Neely, et al., 1997). Performance measures are needed in the organization to evaluate how well the firm functions. The perspective being taken here is that 
a suite of measures are needed that will reflect objectively and consistently the quality of the strategic decisions that have been made within firms (Chakravarthy, 1986). Thus research adopt organizational performance based on BPPSPAM criteria to measure corporate performance in term four aspects related to financial measurements, services delivered, operational, and human resources.

\section{LITERATURE REVIEW}

Few researchers address the link between information management and leadership, and even fewer address the relationship between transformational leadership and knowledge management. Leaders play a crucial role in building and maintaining an organizational knowledge. Managing knowledge requires a conscious effort on the part of leaders at all levels of the organization to manage three key knowledge processes: creating, sharing and exploiting knowledge. Transformational leadership theory provide a foundation for understanding how leaders impact the cultivation of knowledge (Conger \& Kanungo, 1998). Some theorists argue that effective leading organizational knowledge processes is essential to achieving and sustaining a competitive advantage (Teece, 1998). Based on the characteristics of knowledge conversion, Bryant (2003) suggested that transformational leadership influences how individuals approach, interpret, and establish knowledge conversion at work. In fact, the characteristics of transformational leadership facilitate effective knowledge-conversion processes (Bryant, 2003). Based on these and other studies, it is hypothesized that knowledge management positively contributes to organizational performance. Politis (2001) found that self-management, transformational, and transactional leadership styles are related to dimensions of knowledge acquisition. Bryant (2003) argued that there is a clear relationship between transformational leadership and knowledge management in organizations.

H1: Transformational leadership impacts positively on knowledge conversion processes

Organizational culture is an intangible assets of a company. It is about beliefs, values, norms, and attitudes that manage how organization members behaving in everyday life in an organization. Tseng (2011) explores the impacts of hierarchical culture on the effectiveness of the knowledge management processes. Wang et al. (2011) finds that organizational culture comprises a firm's climate that informally and tacitly defines how the firm develops and uses knowledge, thus it has a significant effect on knowledge creation capability. Another researchers found that organizational culture or corporate culture has a positive effect on knowledge management (DeLong \& Fahey, 2000; Alavi \& Leidner, 2005), as well as impact on individual willingness to share knowledge in organization. Nonaka \& Takeuchi (1995) emphasized the important of organizational culture for exchange and communicate tacit knowledge. Based on those literature review, we could structure such hypothesis. (SECI)

$\mathrm{H} 2$ : Organizational culture impacts positively on knowledge conversion processes

The development of strategy involves extensive and intensive knowledge activities. Because knowledge is highly specific and personal, created knowledge is difficult to transform into collective organizational memory and practical use (Grant, 1996; Szulanski, 1996). Knowledge creation processes such as socialization, externalization, combination, and internalization describe a spiral of interactions between explicit and tacit knowledge (Nonaka, 1994; Nonaka and Konno, 1998). The SECl model of knowledge creation allows firms to exchange and transform knowledge continuously and dynamically through a series of self-transcendental processes (Nonaka and Konno, 1998; Nonaka et al., 2000a). When developing and implementing new venture strategy, the dynamic spiral of knowledge creation plays a critical role in facilitating the conceptualization and actualization of strategy.

H3: Strategy impacts positively on knowledge conversion processes (SECI).

Knowledge is well known as a strategic source (Grant, 1996). The ability to create and use knowledge allows a firm to develop a sustainable competitive advantage because of the valuable, rarity, hard to imitate characteristic of knowledge. Previous studies have suggested 
the critical role of knowledge creation in the success of organizations (Kogut and Zander,2003; Nonaka and Takeuchi, 1995; Gold et al., 2001). Organizations with better knowledge creation process can connect knowledge in new and distinctive ways and provide value to customers (Nonaka and Konno, 1998; Lee and Choi, 2003). Knowledge management encompasses managerial efforts in facilitating acquisition, creation, storing, dissemination, developing and using activities of individual or group in organization (Demarest, 1997; Rowley, 2001; Soliman \& Spooner, 2000; Bergeron, 2003). Other researchers also found that an increasing of industry's competition level will effect a company competitive through developing key success factors of knowledge management (Ling et al., 2008; Darr et al., 1995).

$\mathrm{H} 4$ : Knowledge conversion processes (SECl) impacts positively on organizational performance

Organizational culture refers to shared assumptions, values, and norms (Schein, 1985) and a source of sustained competitive advantage (Barney, 1991). Empirical research shows that it is a key factor to organizational effectiveness (Lok \& Crawford, 1999; Denison, 1990; Gordon and Di Tomaso, 1992; Peters and Waterman, 1982). In particular, Lok \& Crawford (1999) use Wallace's organizational culture dimensions (bureaucratic, innovative, and supportive) to show the it's impact on workers' commitment. Denison and his colleagues (Denison, 1990; Denison and Mishra, 1995; Denison and Neale, 1996; Fey and Denison, 2003) identified and validated four dimensions of organizational culture that are conducive to organizational effectiveness: adaptability, consistency, involvement, and mission. Adaptability refers to the degree to which an organization has the ability to alter behavior, structures, and systems in order to survive in the wake of environmental changes. Consistency refers to the extent to which beliefs, values, and expectations are held consistently by members. Involvement refers to the level of participation by an organization's members in decision making. Mission refers to the existence of a shared definition of the organization's purpose.

H5: Organizational culture impacts positively on organizational performance.

According to Gatignon and Xuereb (1997), strategic orientation is the principle that directs the organizational activities and behaviors essential for the performance of the firm. It represents different mechanisms of organizational adaptation. The relationship between strategic orientation and performance has been an important topic in management studies and has attracted the attention of scholars for decades (Acquaah, 2007; Venkatraman, 1989). However, there still exists a lack of consensus on the conceptualization and measurement of strategic orientation. As a result, conflicting theoretical perspectives are employed; and contrasting methodologies are utilized (Morgan \& Strong, 2003). Hakala (2010) described it as templates for the ways of conducting business activity to maintain and improve the organizational performance. The strategic orientation of the firm may be considered a key element with important implications for the management and efficiency of SMEs (Snow and Hrebiniak 1980). Depending on the strategic orientation adopted, the firm may emphasize more or less aspects such as technological position, innovation, organizational design, and personnel management (Conant, Mokwa, and Varadarajan 1990). These aspects of management can largely determine firm performance and business efficiency (Slater and Narver 1993).

H6: There is a significant impact of strategy on organizational performance in regional water supply company of West Nusa Tenggara.

The transformational leader wants to achieve results beyond what is normal and sets higher of the team's mission, stimulates employees to think innovatively about a problem or task, and places the group goals over personal self-interest (James, 2005).Transformational leaders' behaviors are influential in motivating the employees and to make them more aware of the task outcomes and also to stimulate their order needs and develop their self-interest (Elenkov, 2002) for the organization's performance. In his study on the transformational leadership practices in Russian companies; Elenkov (2002) examined the former impact on organizational performance. Using a Multifactor Leadership Questionnaire, he analyzed the leadership behavior of 253 leaders. The analysis underlined a strong correlation between 
transformational leadership practices and organizational performance. In their study on the connection between the transformational leadership style and organizational performance, (Zhu et al. 2005) identified within 170 companies from Singapore, a positive relationship between the transformational leadership and the organizational performance. They also demonstrated that effective human resources management arbitrates the relationship between leadership and performance through increased commitment, higher motivation and intellectual motivation.

$\mathrm{H7}$ : There is a significant impact of transformational leadership on organizational performance in regional water supply company of West Nusa Tenggara.

Transformational leaders have charisma, provide inspiration and promote intellectual stimulation (Bass, 1999; Bass and Avolio, 2000; Conger, 1999). Charisma generates the pride, faith and respect that leaders work to encourage their employees to have in themselves, their leaders, and their organizations. Transformational leaders provide inspiration by motivating their followers, largely through communication of high expectations. Such leaders also promote intellectual stimulation by promoting employees' knowledge so that employees can be innovative in their approach to problem solving and solutions. Various studies analyze the influence of transformational leadership on organizational performance through intermediate constructs such as culture (e.g., Ogbonna and Harris, 2000), entrepreneurship (e.g., García Morales et al., 2006), knowledge management (e.g.,Gowen et al., 2009), human-capital-enhancing human resource management (Zhu et al., 2005), competitive strategies (e.g., Menguc et al., 2007), and absorptive capacity (e.g., Morales et al., 2008a, b). However, understanding of the processes through which the leader exerts this influence is still limited and largely speculative (Bass, 1999; Conger, 1999). This investigation seeks to analyze empirically whether transformational leadership exerts this influence on organizational performance through the intermediate influence of knowledge management (SECl).

H8: Knowledge management fully mediate the impact of transformational leadership on organizational performance in regional water supply companies of West Nusa Tenggara.

Previous research shows that culture as a key factor to organizational performance (Deal and Kennedy, 1982; Denison, 1990; Gordon and Di Tomaso, 1992 Peters and Waterman, 1982). In particular, Denison and his colleagues (Denison, 1990; Denison and Mishra, 1995; Denison and Neale, 1996; Fey and Denison, 2003) identified and validated four dimensions of organizational culture that are conducive to organizational performance: adaptability, consistency, involvement, and mission. Another studies imply a positive relationship between Denison's organizational culture and Nonaka \& Takeuchi's SECI mode includes (Andreeva \& Ikhilchik, 2014; Kaur et al., 2012; Gray \& Densten, 2013; Li et al., 2012). Organizational culture does not directly lend its influence on organizational performance; rather, it exerts its influence through shaping the behavior of organizational members. In an ambiguous and uncertain world, the most important part of decision-making is to digest the information from the environment to structure the unknown.

H9: Knowledge management fully mediate the impact of organizational culture on organizational performance in regional water supply companies of West Nusa Tenggara.

Previous research suggest a positive association between organizational strategy and knowledge management. For example, Pedler et al. (1991) highlight the importance of an analytical approach to strategy that contributes to learning. Senge (1990) stresses the ability to envision the future that is crucial to the learning organization. Watkins and Marsick (1996) emphasize a proactive approach to new learning and new markets in establishing a learning organization (Watkins and Marsick, 1996). The knowledge-based view considers the firm as a set of knowledge assets and the role of the firm as creating and deploying these assets to create value (Grant, 1996). Organizational strategy can then be perceived as the organization's plan of creating and deploying knowledge assets. Knowledge management partially carries the influence of strategy through defining what strategic knowledge is, coordinating critical knowledge transfers, and guiding key knowledge exploitation efforts which could result in enhanced effectiveness. Apart from the path of knowledge 
management, strategy impacts organizational performance through other channels such as control systems and resource sharing schemes.

$\mathrm{H} 10$. Knowledge management fully mediates the impact of strategy on organizational performance in regional water supply companies of West Nusa Tenggara.

\section{METHODS OF RESEARCH}

A positivist paradigm is applied that emphasize on theoretical testing where data collected by using questionnaire survey and an in depth interview to get a valid and reliable result (Cooper \& Schindler, 2011). There are 8 regional water supply companies in West Nusa Tenggara Province as sample survey (saturated sample). 70 respondents, consist of 18 top level managers and 52 middle level managers, selected based on purposive sampling according to criteria gave their perceptional opinion about the relationship between exogenous and endogenous variables. The identification and selection of sampling respondents was considered with attention being paid to the knowledge understood within the firm concerning the data generation requirements of the survey. So as to limit measurement error, it was determined that related Head of Administrative and Technique in each sampling unit could be accepted as the respondent due to their understanding of decision making processes.

Survey items were adapted from existing instruments used in past research and each respondent's perceptional answer is based on five score of Likert scale. To measure subjects' perceptions of transformational leadership, the Multifactor Leadership Questionnaire (MLQ-5x/Short Form) (Bass \& Avolio, 1995) was employed. For the purpose of this study, four subscales were loaded together and used as a measure for transformational leadership (Charisma, Inspiration, Individualized Consideration, and Intellectual Stimulation.

Measures assessing organizational culture were adapted from Denison and his colleagues (Denison, 1990; Denison and Mishra,1995; Denison and Neale, 1996; Fey and Denison, 2003) that encompassed four functional dimensions: adaptability, consistency, involvement, and mission. The scale measures to what extent an organization is perceived to display the four dimensions of characteristics, for example, to what extent "we have a shared vision of what the organization will be like in the future. Venkatraman's (1989) STROBE (Strategic Orientation of Business Enterprise) framework was utilized in this study to represent organizational strategy. The reason why it was used instead of strategic typologies is that it depicts the intensity of characteristics of strategy rather than putting them into categories. STROBE measures to what extent the respondents perceive their organization's strategy as displaying three characteristics including analysis, futurity, and riskiness. To measure the knowledge creation process based on the four modes of knowledge conversion theory, we developed a questionnaire based on previous research (Tseng, 2010) and empirically examined the item internal consistency and construct validity to ensure the general validity issue of the instrument. To measure the perceived levels of organizational performance based on BPPSPAM measurement consists of 4 dimensions i.e. financial, services, operational, and human resources dimensions where each part has five measurement items.

Following Hwang \& Takane (2004), Generalized Structure Component Analysis (GSCA) was conducted for assessing confirmatory measurement models structural models. As the name suggests, GSCA lies in the tradition of component analysis. It substitutes components for factors as in PLS. Unlike PLS, however, GSCA offers a global least squares optimization criterion, which is consistently minimized to obtain the estimates of model parameters. GSCA is thus equipped with an overall measure of model fit while fully maintaining all the advantages of PLS (e.g., less restricted distributional assumptions, no improper solutions, and unique component score estimates). In addition, GSCA handles more diverse path analyses, compared to PLS. For example, it can easily fit the same path model to more than one group with optional impositions of across-group constraints, which PLS cannot accommodate (Hwang \& Takane, 2004). 
Descriptive analysis. GSCA analysis apply measurement of goodness of fit based on score of FIT, AFIT (adjusted FIT), GFI (goodness of fit index), and SRMR (Standard Root Mean Square). Table 1 below shows goodness of fit of structural model and overall goodness of fit.

Table 1 - Goodness of FIT Structural Model

\begin{tabular}{|c|c|c|}
\hline \multicolumn{2}{|c|}{ Model Fit } & Reference Score \\
\hline FIT & 0.595 & $0-1$ \\
\hline AFIT & 0.598 & $0-1$ \\
\hline GFI & 0.978 & cut-off $\geq 0.90$ \\
\hline SRMR & 0.158 & cut-off $\leq 0.08$ \\
\hline NPAR & 45 & - \\
\hline
\end{tabular}

Table above shows that all fit model are over the minimum reference score. Fit's score of 0.595 mean that $59 \%$ variance data can be explained by the model. The score may fall between 0 to 1 mean that the closer to 1 score the better model explain the variance. Meanwhile GFI (goodness fit index) revealed a score above cut-off value.

This measurement consist of convergent validity describes correlation between indicators and latent variable's score and the score obtained should be between 0.5 to 0.6 of loading factor; discriminant validity (AVE) recommended $>0.5$; and internal consistency reliability (alpha) measured by composite reliability that describes the relationship between latent variable and block indicators, the value more than 0.60 is better. Overall convergent validity scores are greater that 0.6 mean that all indicators are suitable to describe its related latent variable. The lowest convergent validity based on GSCA analysis obtained by intellectual stimulation indicator of transformational leadership variable (0.670), and the highest scored by operational aspect indicator of organizational performance variable (0.889).

Discriminant validity and composite reliability value are shown in the following table.

Table 2 - Value of AVE and Alpha

\begin{tabular}{|c|c|c|}
\hline Variable & AVE & Alpha \\
\hline Transformational Leadership (X1) & 0.504 & 0.669 \\
\hline Organizational Culture (X2) & 0.550 & 0.722 \\
\hline Strategic Orientation (X3) & 0.551 & 0.591 \\
\hline Knowledge Management (Y1) & 0.613 & 0.783 \\
\hline Organizational Performance (Y2) & 0.643 & 0.812 \\
\hline
\end{tabular}

Hypothesis testing and path coefficient of direct impact will be conducted in five variable latent where there are 7 direct relationships between exogenous variables and endogenous variables. The result shown by path coefficient value and critical value at significant value of alpha $=0.05$.

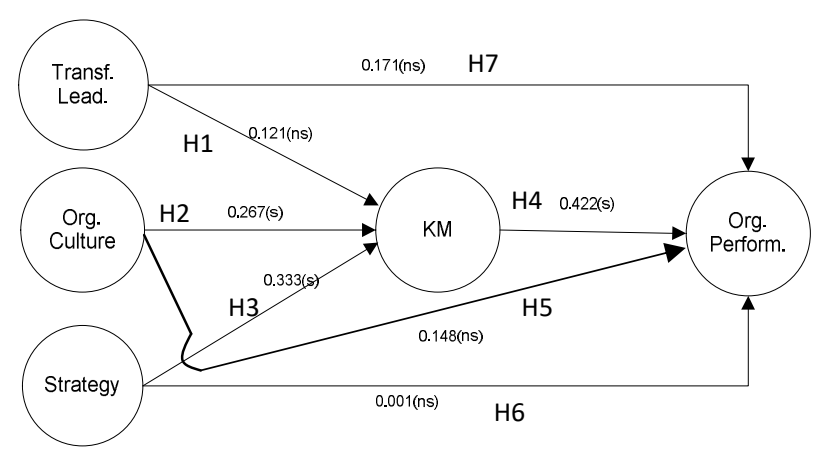

Figure 1 - Path Coefficient and Hypotheses Testing Diagram 
Based on diagram above, we could find a complete meaning of all value in the table below.

Table 3 - Path Coefficient of Direct Impact and Hypotheses Testing

\begin{tabular}{|c|c|c|c|c|c|}
\hline Hypothesis & Relationship & Path Coefficient & CR & \multicolumn{2}{|c|}{ Meaning } \\
\hline $\mathrm{H} 1$ & $\mathrm{TL}(\mathrm{X} 1) \rightarrow \mathrm{KM}(\mathrm{Y} 1)$ & 0.121 & 0.133 & NS & Rejected \\
\hline $\mathrm{H} 2$ & $\mathrm{OC}(\mathrm{X} 2) \rightarrow \mathrm{KM}(\mathrm{Y} 1)$ & 0.267 & $2.1^{*}$ & significant & accepted \\
\hline $\mathrm{H} 3$ & Strategy $(\mathrm{X} 3) \rightarrow \mathrm{KM}(\mathrm{Y} 1)$ & 0.333 & $3.15^{*}$ & significant & accepted \\
\hline $\mathrm{H} 4$ & $\mathrm{KM}(\mathrm{Y} 1) \rightarrow \mathrm{OP}(\mathrm{Y} 2)$ & 0.422 & $2.9^{*}$ & significant & accepted \\
\hline $\mathrm{H} 5$ & $\mathrm{OC}(\mathrm{X} 2) \rightarrow \mathrm{OP}(\mathrm{Y} 2)$ & 0.148 & 1.04 & NS & Rejected \\
\hline $\mathrm{H} 6$ & Strategy $(\mathrm{X} 3) \rightarrow \mathrm{OP}(\mathrm{Y} 2)$ & 0.001 & 0.01 & NS & Rejected \\
\hline $\mathrm{H} 7$ & $\mathrm{TL}(\mathrm{X} 1) \rightarrow \mathrm{OP}(\mathrm{Y} 2)$ & 0.171 & 0.118 & NS & Rejected \\
\hline
\end{tabular}

As hypotheses 2 and 3 predict, both organizational culture and strategy are significantly related to knowledge management as well as relationship between knowledge management and organizational performance (hypotheses 4). On the other hand, hypotheses 1 is not significantly related to both knowledge management and organizational performance. There is also found that hypotheses 5,6 , and 7 are all not significantly related to organizational performance, judging from the results of bevariate correlations (as shown in Table 3). Knowledge management $(C R=2.9, p>0.05)$ demonstrated a positive and significant relationship with organizational performance. Organizational culture $(C R=1.04, p>0.05)$, and strategy $(C R=0.01, p>0.05)$ also demonstrated a positive relationship with organizational effectiveness but not significant. Both variables organizational culture $(C R=2.1, p>0.05)$ and strategy $(C R=3.15, p>0.05)$ revealed a positive and significant relationship with knowledge management, but not for that of transformational leadership. Based on the table above, three hypotheses $(\mathrm{H} 2, \mathrm{H} 3$, and $\mathrm{H} 4)$ are accepted and the rests are rejected.

This path coefficient shows an indirect impact of independent variables (transformational leadership, organizational culture, and strategy) on dependent variable (organizational performance) mediated by knowledge management (SECl model). Based on this statistical processes, it can be concluded whether SECI Model fully mediated (complete mediated) that relationship or not.

Table 4 - Path Coefficient of Mediating Impact

\begin{tabular}{|c|c|c|c|c|c|c|c|}
\hline \multirow{2}{*}{ No } & \multirow{2}{*}{ Relationship } & \multirow{2}{*}{ Mediating variable } & \multicolumn{4}{|c|}{ Path Coefficient } & \multirow{2}{*}{ Meaning } \\
\hline & & & $\mathrm{C}$ & $\mathrm{d}$ & $\mathrm{a}$ & $\mathrm{b}$ & \\
\hline 1 & $\mathrm{OC}(\mathrm{X} 2) \rightarrow \mathrm{OP}(\mathrm{Y} 2)$ & KM & $0.267^{*}$ & $0.422^{*}$ & $0.148^{\text {ns }}$ & - & Complete Mediation \\
\hline 2 & Strategy $(\mathrm{X} 3) \rightarrow \mathrm{OP}(\mathrm{Y} 2)$ & KM & $0.333^{*}$ & $0.422^{*}$ & $0.001^{\mathrm{ns}}$ & - & Complete Mediation \\
\hline 3 & $\mathrm{TL}(\mathrm{X} 1) \rightarrow \mathrm{OP}(\mathrm{Y} 2)$ & KM & $0.121^{\mathrm{ns}}$ & $0.422^{*}$ & $0.171^{\mathrm{ns}}$ & - & Not mediated \\
\hline
\end{tabular}

Hypothesis 8, 9 and 10 predict that knowledge management fully mediates the relationship between transformational leadership, organizational culture, and organizational strategy with organizational performance. The findings supported the hypothesis 9 and 10 . Both organizational culture and strategy had a positive and significant influence on knowledge management (value of CR are 0.267 and 0.333 , respectively), and a positive influence of knowledge management on organizational performance ( $C R=0.422)$. Furthermore, the result also show a direct effect of knowledge management on organizational performance $(C R=0.422, p<0.01)$. In addition to these effects, the study shows indirect effects of organizational culture \& strategy on organizational performance. Based on these findings, it can be concluded that knowledge management fully mediates the relationship between both organizational culture and strategy on organizational performance although the direct relationship between these two variables on organizational performance is not significant. On the other hand, this study shows that knowledge management does not mediate indirect relationship between transformational leadership on organizational performance. Thus, this finding does not support the hypotheses 8 . 


\section{CONCLUSION}

Previous researches show that a leader has a critical role in knowledge management processes in terms of delivering vision, how to motivate followers, system building, as well as determining organizational structure in order to achieve knowledge conversion to be a competitive advantage (Nonaka \& Toyama, 2005; Nonaka et al., 2006; Joshi, 2000; Yeh et al., 2006; Wong, 2005; Sin et al., 2009). Nonaka et al. (2006), in particular, found that a leader role is to facilitate knowledge creation rather than to control, or to direct. Therefore, a flexible characteristic of a leader is required to success rather than a mechanistic control.

The overall pattern of effects between exogenous and endogenous variables in the GSCA model is consistent with hypotheses stated, but only some of the path tested were confirmed. Of the 7 paths tested between these variables, 3 were significant. For the transformational leadership variable, there is no significant impact on both knowledge management (as mediating variable) and organizational performance. Organizational culture and strategic orientation have a positive and significant impact on knowledge management, but contrary to the organizational performance. However, knowledge management has a positive and significant effect on organizational performance.

Knowledge management was found to fully mediate organizational culture and strategy's influence on organizational performance. This finding suggests that how well knowledge is managed is largely associated with how well cultural values are translated into value to the organization. Further, culture has a greater contribution to knowledge management than transformational leadership variable. This may be due to the fact that culture determines the basic beliefs, values, and norms regarding the why and how of knowledge generation, sharing, and utilization in an organization. This finding strengthens the call for attention to creating an organizational culture that is conducive to learning and knowledge management (Davenport and Prusak,1998; DeLong and Fahey, 2000).

\section{REFERENCES}

1. Acquaah, Moses \& Yasai-Ardekani, Masoud, 2008, Does the implementation of a combination competitive strategy yield incremental performance benefits ? A new perspective from a transition economy in Sub-Saharan Africa, Journal of Business Research, 61, 346-354.

2. Alavi, Maryam, Kayworth, Timothy R. \& Leidner, Dorothy E., 2005, An Empirical Examination of the Influence of Organizational Culture on Knowledge Management Practices, Journal of Management Information Systems, 22 (3), 191-224.

3. Barney, J. B., 1995, Looking inside for competitive advantage, Journal of Management Executive, 9(4), 49-60.

4. Barney, Jay B., 1986, Types of competition and the theory of strategy: toward an integrative framework, Academy of Management Review, 11 (4), 791-800.

5. Bass, Bernard M, 1985, Leadership: Good, Better, Best, Leadership and Performance Beyond Expectations, The Free press, 26-40.

6. Bergeron, Bryan, 2003, Essentials of Knowledge Management, Hoboken, New Jersey, John Wiley \& Sons, Inc.

7. Bryant, S. E. (2003), The Role of Transformational and Transactional Leadership in Creating, Sharing and Exploiting Organizational Knowledge, The Journal of Leadership and Organizational Studies, Vol. 9, No. 4, pp. 32-44

8. Chakravarthy B.S., Measuring strategic performance, Strategic Management Journal, 1986;7:437- 58.

9. Conger, J.A., 1999, Charismatic and transformational leadership in organizations: An insider's perspective on these developing streams of research, Leadership Quarterly, 10: 145-169.

10. Conant J.S., Mokwa M.P., Varadarajan P.R., Strategic types, distinctive marketing ompetencies, and organizational performance, Strategic Management Journal, 1990;11: 365- 83. 
11. Cooper, R. Donald \& Schindler, S. Pamela, 2011, Business Research Methods, McGraw Hill International Edition, Eleventh Edition

12. Darr, Eric D., Argote, Linda, Epple, Dennis, 1995, The Acquisition, Transfer, and Depreciation of Knowledge in Service Organization: Productivity in Franchises, Management Science, 41 (11), 1750-1762.

13. De Long, David W. \& Fahey, Liam, 2000, Diagnosing cultural barriers to knowledge management, Academy of Management Executive, 14 (4), 113-127.

14. Demarest, Marc, 1997, Understanding Knowledge Management, Long Range Planning, 30 (3), 374-384.

15. Denison, Daniel R. \& Mishra, Aneil K., 1995, Toward a theory of organizational culture and effectiveness, Organization Science, 6 (2), 204-223.

16. Denison \& Neale, 1996, Denison Organizational Culture Survey, Facilitator Guide, Ann Arbor, MI: Aviat.

17. Denison, Daniel R., 1984, Bringing corporate culture to the bottom line, Organizational Dynamics.

18. Elenkov, Detelin S., 2002, Effects of leadership on organizational performance in Russian companies, Journal of Business Research, 55, 467-480.

19. Fey, Carl F. \& Denison, Daniel R., 2003, Organizational culture and effectiveness: Can American theory be applied in Russia ?, Organization Science, 14 (6), 686-706.

20. Gold, Andrew H., Malhotra, Arvind, \& Segars, Albert H., 2001, Knowledge Management: Organizational Capabilities Perspective, Journal of Management Information Systems, 18

21. Gordon, George G. \& DiTomaso, Nancy, 1992, Predicting corporate performance from organizational culture, Journal of Management Studies, 29 (6), 783-798.

22. Grant, R. M. (1996), Toward a knowledge-based theory of the firm, Strategic Management Journal, (17), Winter Special Issue, 109-22.

23. Gray, J. H. \& Densten, I. L., (2005), "Towards an Integrative Model of Organizational Culture and Knowledge Management", International Journal of Organizational Behavior, 2 (9), 594-

24. Hwang, Heungsun \& Takane, Yoshio, 2004, Generalized Structured Component Analysis, Psychometrika, vol. 69, No. 1, 81-89.

25. Kaplan R.S. \& Norton D.P., The balanced scorecard - measures that drive performance, Harvard Business Review, 1992;70:71- 9.

26. Kogut, Bruce \& Zander, Udo, 1992, Knowledge of the Firm, Combinative Capabilities, and the Replication of Technology, Organization Science.

27. Lee, Heeseok \& Choi, Byounggu, 2003, Knowledge Management Enablers, Processes, and Organizational Performance: An Integrative View and Empirical Examination, Journal of Management Information Systems, 20 (1), 179-228.

28. Lin, C. H., Peng, C. H., \& Kao, D. T. (2008), The innovativeness effect of market orientation and learning orientation on business performance, International Journal of Manpower, 29(8), 752-772.

29. Lok, Peter \& Crawford, John, 1999, The relationship between commitment and organizational culture, subculture, leadership style and job satisfaction in organizational change and development, Leadership \& Organization Development Journal, 20 (7), 365373.

30. Lok, Peter \& Crawford, John, 2003, The effect of organizational culture and leadership style on job satisfaction and organizational commitment - A cross-national comparison, Journal of Management Development, 23 (4), 321-338.

31. Morales, Victor Jesus Garcia, Barrionuevo, Maria Magdalena Jimenez \& Gutierrez, Leopoldo Guiterrez, 2011, Transformational leadership influence on organizational performance through organizational learning and innovation, Journal of Business Research.

32. Morgan Robert E., \& Strong Carolyn A., 2003, Business performance and dimensions of strategic orientation, Journal of Business Research. 
33. Neely, Andy, Bourne, Mike \& Kennerly, Mike, 2000, Performance measurement system design: developing and testing a process-based approach, International Journal of Operations \& Production Management.

34. Neely, Andy, Richards H., Mills J., Platts K., \& Bourne M., Designing performance measures: a structured approach, International Journal of Operations \& Production Management, 1997; 17: 1131-1152

35. Nonaka, Ikujiro \& Takeuchi, Hirotaka, 1995, The Knowledge-Creating Company: How Japanese Companies Create the Dynamics of Innovation, Oxford University Press, New York.

36. Nonaka, Ikujiro, 1994, A Dynamic Theory of Organizational Knowledge Creation, Organization Science.

37. Nonaka, Ikujiro, 2006, Creating Sustainable Competitive Advantage Through Knowledgebased Management, http://www.google.com.Download September 2011.

38. Nonaka, Ikujiro, Toyama, Ryoko \& Konno, Noboru, 2000, SECI, Ba and leadership: a unified model of dynamic knowledge creation, Long Range Planning, 33, 5-34.

39. Ogbonna, Emmanuel \& Harris, Lloyd C., 1998, Managing Organizational Culture: Compliance or Genuine Change?, British Journal of Management, Vol. 9, 273-288.

40. Peters, Thomas J., \& Waterman, Robert H., Jr., 1982, In Search of Excellence - Lessons from America's Best-Run Companies, HarperCollins Publisher, USA.

41. Politis, John D., 2001, The relationship of various leadership styles to knowledge management, Leadership \& Organizational Development Journal, 354-364.

42. Rowley, Jennifer, 1999, What is knowledge management ?, Library Management, 20 (8).

43. Saenz, J., et al., 2009. Knowledge sharing and innovation performance: A comparison between high - tech and low- tech companies, Journal of Intellectual Capital, Vol.10, No.1, pp.22 -

44. Schein, Edgar H., 2004, Organizational Culture and Leadership, John Wiley \& Sons, Inc., San Fransisco, CA.

45. Slater, Stanley F. \& Olson, Eric M., 2000, Strategy type and performance: The influence of sales force management, Strategic Management Journal, 21, 813-829.

46. Snow, Charles C. \& Hambrick, Donald C., 1980, Measuring organizational strategies: some theoretical and methodological problems, Academy of Management Review, 5 (4), 527-538.

47. Soliman, Fawzy \& Spooner, Kery, 2000, Strategies for implementing knowledge management: role of human resources management, Journal of Knowledge Management, 4 (4), 337-345.

48. Teece, David D., Pisano, Gary, Shuen, Amy, 1997, Dynamic capabilities and strategic

49. Tseng, Shu-Mei, 2010, The correlation between organizational culture and knowledge conversion on corporate finance, Journal of Knowledge Management, 14 (2), 269-284.

50. Venkatraman N. \& Ramanujam V., Measurement of business performance in strategy research: a comparison of approaches, Academy Management Review, 1986; 11:80114.

51. Venkatraman N., 1989, Strategic orientation of business enterprises: the construct, dimensionality, and measurement, Management Science, 35:942-62. 